\title{
Modeling the Stress-Strain Behavior and Hot Tearing During Direct Chill Casting of an AZ31 Magnesium Billet
}

\author{
H. Hao ${ }^{1}$, D. M. Maijer ${ }^{2}$, M. A. Wells ${ }^{3}$, Andre Phillion ${ }^{4}$ and S.L. Cockcroft ${ }^{2}$ \\ ${ }^{1}$ Department of Materials Engineering, Dalian University of Technology, 2\# Linggong Road, \\ Dalian, Liaoning Province, P.R. China 116024 \\ ${ }^{2}$ Department of Materials Engineering, University of British Columbia, 309-6350 Stores \\ Road, Vancouver, B.C., Canada V6T 1 Z42 \\ ${ }^{3}$ Department of Mechanical and Mechatronics Engineering, University of Waterloo, 200 \\ University Ave East, Waterloo, Ontario, Canada, N2L 5G8 \\ ${ }^{4}$ School of Engineering, University of British Columbia | Okanagan, FIPKE 305 - 3333 \\ University Way, Kelowna, BC V1V 1V7
}

\begin{abstract}
Quantitative knowledge of the thermal mechanical history experienced during direct chill (DC) casting aids the scientific understanding of the process especially in terms of defect formation such as hot tearing. In this work, a thermo-mechanical finite element (FE) model has been developed to simulate the DC casting of magnesium alloy AZ31 billets. The mathematical model simulates the evolution of temperature, stress, and strain within the billet during an industrial DC casting process. These quantities were then used to calculate the evolution in pressure, and hence hot tearing tendency, within the semi-solid regime via the Rappaz-Drezet-Gremaud (RDG) criterion. The temperature predictions were validated against experimental thermocouple data measured during a plant trial at an industrial magnesium DC casting facility. In addition, the residual elastic strains predicted by the model were compared to residual strain measurements made at the Canadian Neutron Beam Centre (CNBC) located in Chalk River, Ontario, Canada using a magnesium billet produced during the industrial casting trial. The validated model was then used to quantitatively assess the impact of casting speed on the hot tearing tendency in AZ31 billets.
\end{abstract}

\section{INTRODUCTION}

DC casting is the main process for producing the precursor material for many non-ferrous (i.e., zinc, aluminum and magnesium) wrought products as well as the re-melt stock for cast products. With the recent renewed interest in producing wrought magnesium products, the DC casting process is receiving significantly more attention from the standpoint of process optimization. As with the DC casting of aluminum alloys, the formation of hot tears is a severe quality issue that may occur during the DC casting of magnesium ${ }^{[1]}$. This defect, which can cause the entire billet to be rejected, results in decreased process throughput and increased casting inspection to ensure that billets with hot tears are not transferred to 
downstream processing operations. Experiments and industrial experience have revealed that the problem is most prevalent during the transient start-up phase of the process. A detailed literature review on the subject has been previously provided by Eskin et al. ${ }^{[2]}$. The challenge with hot tearing is that it is a complex defect since under identical casting conditions, some billets will tear while others will not. Hence, its prediction and therefore control is difficult.

Although the DC casting process has been the subject of scientific study since its beginning in the 1930s, many technical challenges still exist ${ }^{[3,4]}$. These challenges limit the efficiency of the process as well as the alloy composition and product geometry. Research focused on hot tear formation indicates that hot tears occur when the strain accumulated in regions of the billet that are above the solidus temperature exceeds the semi-solid ductility limit ${ }^{[5-10]}$. This accumulation of strain is due primarily to the differences in thermal history experienced between the center and surface of the billet. Thus, understanding the evolution of thermal stresses and strains is a prerequisite to developing a more fundamental understanding of the hot tearing phenomenon and to identifying processing paths under which hot tearing can be mitigated. Over the years, computer modeling has provided a powerful means to investigate and understand the evolution of thermal and mechanical phenomena during the DC casting process ${ }^{[11-20]}$.

In the current work, a previously developed axi-symmetric model describing the evolution of temperature during the DC casting of magnesium AZ31 billets has been extended to predict the evolution of stress and strain in order to predict the susceptibility of the process to hot tearing using the Rappaz-Drezet-Gremaud (RDG) criterion ${ }^{[21]}$. The as-cast constitutive behavior of the AZ31 alloy was established from compression experiments made using a Gleeble 3500 thermo-mechanical simulator over the temperature range $25-400^{\circ} \mathrm{C}$. The other material properties required for the mechanical analysis were taken from the literature. To validate the model, the stress/strain predictions were compared against residual stress measurements made on an industrially DC cast magnesium AZ31 billet.

\section{BACKGROUND}

Mathematical modeling of the DC casting process has been the focus of study since the middle of the twentieth century. However, since Adenis et al. ${ }^{[12]}$ reported their modeling work on DC casting of magnesium in 1962, very little other work has been done on this alloy system. Hibbins ${ }^{[13]}$ proposed a series of heat transfer boundary conditions for magnesium DC castings under steady-state conditions based on experimental measurements. The proposed heat transfer coefficients varied with location but were constant with respect to temperature. 
Hai et al. ${ }^{[14]}$ developed a comprehensive finite element (FE) thermal model of the DC casting of AZ31 billets capable of describing both the start-up and steady state regimes. This model was extensively validated using industrial thermocouple measurements from a series of DC casting trials. To date, no attempts to predict stresses, strains, or hot tearing during magnesium alloy DC casting have been reported.

In contrast, a considerable body of work has been reported on modeling the DC casting process in aluminum alloys ${ }^{[15-19]}$. The most recent of these include the majority of the relevant phenomena that are thought to affect heat transfer and stress/strain development: boiling water heat transfer during cooling, water incursion between the base of the ingot and the bottom block, and macroscopic ingot distortions (butt curl and lateral pull-in). There have also been some attempts to integrate various hot tearing criteria into these models. As shown by both Drezet ${ }^{[22]}$ and Suyitno ${ }^{[23]}$, the so-called RDG ${ }^{[21]}$ hot tearing criterion, which incorporates mushy zone pressure drop and strain-rate effects, appears to be the most successful in qualitatively predicting the correct location of hot tearing in DC cast billets. Alternative approaches to predict hot tearing include a strain-based criterion ${ }^{[18,24,25]}$ or a stress-based criterion ${ }^{[26]}$. While significant progress has been made, fully quantitative hot tearing predictions remain elusive, in part due to the stochastic nature of this defect.

\section{MATHEMATICAL MODEL}

A coupled thermal-mechanical axi-symmetric simulation of the DC casting process for magnesium AZ31 cylindrical billets has been developed using the commercial FE package ABAQUS $^{\mathrm{TM}}$. The model domain includes the billet (455 $\mathrm{mm}$ diameter $\mathrm{x} 900 \mathrm{~mm}$ length), dummy block, and the center bolt embedded in the dummy block. Assuming symmetry, only one-half of the cross-section of this geometry was included in the model. A schematic of the model domain is shown in Figure 1, for a billet with a length corresponding to $505 \mathrm{~s}$ of casting time. The domain consists of 3582 elements and 3833 nodes, each approximately 10 $\mathrm{mm} x 10 \mathrm{~mm}$ in size. All three parts of the domain - billet, dummy block, and the centre bolt - were modeled using 4-noded iso-parameteric coupled temperature / displacement elements. To simulate the casting process, a Lagrangian approach was used, whereby the thermal boundary conditions describing the primary and secondary cooling regions were moved up along the domain at a rate consistent with the billet withdrawal velocity. Horizontal layers of billet elements were incrementally added based on the mold filling rate and casting speed.

\footnotetext{
${ }^{\mathrm{T}}$ ABAQUS is a trademark of ABAQUS, Inc., Pawtucket, RI, USA.
} 
The governing partial differential equation for the transient thermal analysis in cylindrical coordinates is:

$\frac{1}{r} \frac{\partial}{\partial r}\left(k(T) r \frac{\partial T}{\partial r}\right)+\frac{\partial}{\partial z}\left(k(T) \frac{\partial T}{\partial z}\right)=\rho c_{p} \frac{\partial T}{\partial t}$

where $r$ and $z$ are the radial and axial directions in $\mathrm{m}$, respectively, $k$ is the thermal conductivity in $\mathrm{W} \mathrm{m}^{-1} \mathrm{~K}^{-1}, T$ is the temperature in $\mathrm{K}, \rho$ is the density in $\mathrm{kg} \mathrm{m}^{-3}$, and $c_{p}$ is the specific heat in $\mathrm{J} \mathrm{kg}^{-1} \mathrm{~K}^{-1}$. The latent heat released during solidification is incorporated into Equation (1) by modifying the specific heat term for temperatures within the solidification interval according to: $c_{p, e}=c_{p}-L \frac{d f_{s}}{d T}$, where $c_{p, e}$ is the equivalent specific heat, $L$ is the latent heat of fusion in $\mathrm{J} \mathrm{kg}^{-1}$, and $\frac{d f_{s}}{d T}$ represents the rate of change of fraction solid with temperature. In the mechanical analysis, the stress and strain increments are derived based on the nodal displacements along with the compatibility and constitutive equations. The resulting total strain vector, $\Delta \varepsilon^{t o t}$ is given by

$\Delta \varepsilon^{t o t}=\Delta \varepsilon^{e l}+\Delta \varepsilon^{t h}+\Delta \varepsilon^{p l}$

where $\Delta \varepsilon^{e}$ is the elastic strain increment, $\Delta \varepsilon^{\text {th }}$ is the thermal strain increment, and $\Delta \varepsilon^{p l}$ is the plastic strain increment. Note that the constitutive equation is based on an elastic / rateindependent plastic material formulation.

\section{A. Initial conditions}

The dummy block and center bolt were assumed to be at a uniform temperature equal to the measured cooling water temperature of $38^{\circ} \mathrm{C}$, as an initial condition. The layers of elements making up the billet were also assumed to be at a uniform temperature, equal to $678^{\circ} \mathrm{C}$, the pour temperature of the melt.

\section{B. Model Boundary Conditions}

The boundary conditions for the mechanical portion of the simulation were relatively simple: deformation was restricted in the $r$ direction along the centerline, and in both the $r$ and $z$ directions for the node located on the centerline at the base of the billet and for the node at the base of the center bolt. A spring element with a moderate spring constant of $100 \mathrm{~N} \mathrm{~m}^{-1}$ was attached to the node at the bottom of the billet on the centerline and to an arbitrary rigid node located below the dummy block / center bolt to suppress separation of the billet from the dummy block as the model does not include gravity forces that if present would keep the 
billet in contact with the dummy block. This spring element aids in avoiding convergence issues associated with rigid body motion and does not alter the results.

As described in Hai et al. ${ }^{[14]}$, the thermal boundary conditions were initially chosen from the literature and then adjusted based on comparisons of the model predictions to measured data. A summary of these thermal boundary conditions is given below, with each of the surfaces $\Gamma_{1}-\Gamma_{7}$ shown also in Figure 1.

(1) Heat losses occurring on the side surfaces of the billet and dummy block are described using an effective heat transfer coefficient, which embodies heat transfer processes during billet-mold contact (primary cooling, $\left.\Gamma_{1}\right)$, radiation and/or conduction across the air gap $\left(\Gamma_{2}\right)$ and heat transport to water sprays (secondary cooling, $\Gamma_{3}$ ).

(2) Heat transfer between the billet base and the dummy block $\left(\Gamma_{4}\right)$ is described by an effective interfacial heat transfer coefficient which includes the effects of gap formation on thermal resistance.

(3) Heat loss from the bottom of the dummy block/center bolt $\left(\Gamma_{5}\right)$ is described by an effective heat transfer coefficient to account for natural convection to the environment.

(4) Heat transfer between the center bolt and the dummy block $\left(\Gamma_{6}\right)$ is described by an effective interfacial heat transfer coefficient.

(5) Heat loss along the center line $\left(\Gamma_{7}\right)$ is assumed to be zero due to axial symmetry. Heat loss across the top of the billet $\left(\Gamma_{8}\right)$ is also assumed to be zero since new material is continuously feed into the mold.

Note that a detailed description of the numeric values for the boundary conditions, and the fitting procedure, is presented in ${ }^{[14]}$. The implementation of these boundary conditions is also described in great detail in ${ }^{[15]}$.

\section{Thermo-physical and Mechanical Properties}

In order to properly simulate DC casting in a thermo-mechanical FE model, the input material properties must be temperature-dependent, and must take into account the transitions at the liquidus temperature $\left(T_{\text {liq }}\right)$, the mechanical coherency temperature $\left(T_{\text {coh }}\right)$, and the solidus temperature $\left(T_{\mathrm{sol}}\right)$. The mechanical coherency temperature is important since it defines the point where the solidifying material is able to develop stress. In this study, $T_{\text {coh }}$ has been assumed to occur at a fraction solid, $f_{\mathrm{s}} \sim 0.90^{[16]}$. The fraction solid / temperature relationship was generated using the computational thermodynamics software, JMatPro ${ }^{\mathrm{TM}}$, and

\footnotetext{
TM JMatPro is a trade mark of Thermotech Ltd,/ Sente Soft Ltd., Guildford, United Kingdom.
} 
has been previously published ${ }^{[14]}$. Based on this database, $T_{\text {liq }}=635^{\circ} \mathrm{C}, T_{\text {coh }}=578^{\circ} \mathrm{C}$, and $T_{\text {sol }}$ $=424^{\circ} \mathrm{C}$ for the $\mathrm{AZ} 31$ alloy.

The thermo-physical properties necessary for the thermal portion of the model included the density, specific heat, thermal conductivity, and heat of fusion for the liquid to solid phase change. Each of these properties except density were temperature dependent. Refer to Hai et al. ${ }^{[14]}$ for a complete description of the thermo-physical properties used in the model.

The elastic modulus, Poisson's ratio, thermal expansion coefficient, and the inelastic constitutive behavior are required for the various materials involved in the mechanical analysis. The relevant mechanical material properties for the dummy block (AA6061) and center bolt, $\left(0.4 \mathrm{wt} \% \mathrm{C}\right.$ steel) were taken from the ASM handbook ${ }^{[27]}$. In the case of AZ31, the first three properties were obtained from a variety of literature sources. The fourth property, the inelastic constitutive behavior of as-cast AZ31, was experimentally measured via compression testing using a Gleeble 3500 thermo-mechanical simulator.

The variation in elastic modulus with temperature for AZ31 is shown in Figure 2. Below $T_{\text {sol }}$, the temperature-dependent elastic modulus reported by Avedesian and Baker ${ }^{[28]}$ was employed. Above $T_{\text {sol }}$, the elastic modulus was linearly decreased from $35 \mathrm{GPa}$ to $15 \mathrm{GPa}$ at

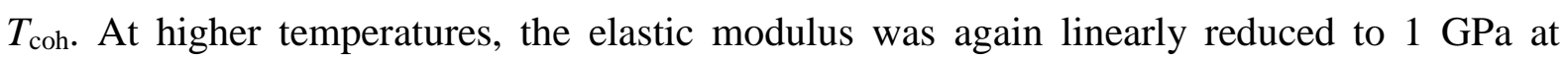
$610^{\circ} \mathrm{C}$ and then to $1 \mathrm{MPa}$ at $T_{\text {liq. }}$. This variation of elastic modulus versus temperature was implemented in an attempt to ensure a low level of stress in the metal above the coherency temperature as the metal will not support load at these temperatures.

The thermal expansion coefficient as a function of temperature was based on the values for pure magnesium ${ }^{[28]}$, and is shown in Figure 3. The total thermal strain resulting from cooling the melt from the pouring temperature to room temperature is also shown. As can be seen in the figure, the thermal contraction is assumed to be zero at temperatures above $T_{\text {coh }}$ since mass feeding will offset this contraction. Hence, the total thermal strain is also zero until this temperature is reached.

The inelastic constitutive behavior is a critical property for simulating the mechanical response of the billet during DC casting. While the temperature-dependent constitutive behavior of AZ31 is available in the literature, these prior measurements were made on wrought material, not on material in the as-cast state. Hence, a series of compression tests were performed on an AZ31 alloy of composition $\mathrm{Mg}-3.21 \mathrm{wt} . \% \mathrm{Al}-1.02 \mathrm{wt} . \% \mathrm{Zn}-$ $0.31 \mathrm{wt} . \% \mathrm{Mn}$ at a strain rate of $0.001 \mathrm{~s}^{-1}$ over a range of temperatures between 25 and $400^{\circ} \mathrm{C}$. This strain rate was chosen based on the authors' previous experience in modeling and characterizing the stress/strain response during DC casting of aluminum alloys. A general 
description of the test procedure was reported by Estey et al. ${ }^{[29]}$ in a companion study. The results of a subset of the experiments performed for this study are shown in Figure 4. As can be seen in the figure, both the flow stress and work-hardening rate decrease with increasing temperature. The results of the compression experiments were then tabulated for use in the model. For temperatures above $400^{\circ} \mathrm{C}$, the yield stress was linearly extrapolated down to a value of $1 \mathrm{MPa}$ with no work hardening (perfectly plastic behavior) at $T_{\text {coh. }}$. The yield stress was then linearly increased to $10 \mathrm{MPa}$ at $T_{\text {liq }}$ in order to minimize plastic strain accumulation

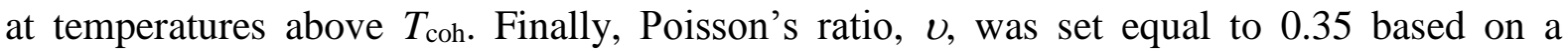
literature reported value ${ }^{[28]}$.

\section{Calculating Hot Tearing Susceptibility Using the RDG Criterion}

During solidification of AZ31, there is a continual decrease in pressure in the interdendritic region, as a result of the volumetric shrinkage due to the phase transformation. In addition, there may also be a volumetric change due to mechanical deformation of the dendritic network that may either increase the need for additional compensatory flow or diminish it depending on whether the net strain is positive (tensile) or negative (compressive). In the absence of porosity, the relative value of this pressure drop, $P_{\text {mush }}$, is given by

$$
P_{\text {mush }}=P_{\rho \mathrm{gh}}-\left(\Delta P_{\text {mech }}+\Delta P_{\text {shrink }}\right)
$$

where $P_{\rho \mathrm{gh}}$ is the metallostatic pressure, $\Delta P_{\text {mech }}$ is the contribution related to deformation, and $\Delta P_{\text {shrink }}$ the contribution related to shrinkage. The basic premise of the RDG criterion ${ }^{[21]}$ is that if $P_{\text {mush }}$ falls below a critical value then a hot tear will occur. Although the critical pressure for hot tear formation is unknown, the combined pressure drop related to deformation and shrinkage, $\Delta P_{\text {mech }}+\Delta P_{\text {shrink }}$, can be used to assess hot tearing susceptibility. The larger the value of this pressure drop, the more prone a location is to hot tearing.

The variation in pressure within the interdendritic region can be determined from a mass balance performed on a small volume element of the mushy zone containing both solid and liquid phases. The average mass conservation equation for this volume element is

$$
\frac{\partial\langle\rho\rangle}{\partial t}+\nabla \cdot\langle\rho v\rangle=0
$$

where the notation $\langle$.$\rangle is used to indicate the values obtained by locally averaging the solid$ and liquid phase components ${ }^{[30]}, \rho$ is the density, and $v$ is the velocity. Assuming the liquid 
velocity is parallel to the direction of the heat flow while the solid deforms perpendicular to the direction of heat flow, this mass balance can be expanded to

$\frac{\partial}{\partial t}\left(\rho_{l}\left(1-f_{s}\right)+\rho_{s} f_{s}\right)+\frac{\partial}{\partial x}\left(\rho_{l}\left(1-f_{s}\right) v_{l, \square}\right)+\frac{\partial}{\partial y}\left(\rho_{s} f_{s} v_{s, \perp}\right)=0$

where $\rho_{l}\left(\rho_{s}\right)$ is the density of the liquid (solid) phase, and $v_{l, \square}\left(v_{s, \perp}\right)$ is the liquid (solid) velocity in their respective directions. The pressure drop that occurs over the entire length of the mushy zone can be related to Equation (5) using the Darcy equation, and thus

$$
\begin{aligned}
& \Delta P_{\text {mech }}+\Delta P_{\text {shrink }}=(1+\beta) \mu \int_{x}^{L} \frac{E}{K} d x+\beta \mu \int_{x}^{L} \frac{F}{K} d x \\
& E=\int_{0}^{x} f_{s} \dot{\varepsilon}_{\perp}^{p l} d x \\
& F=\int_{0}^{x} \frac{d f_{s}}{d t} d x
\end{aligned}
$$

where $\beta$ is the shrinkage factor, given by $\beta=\left(\rho_{s} \rho_{l}^{-1}-1\right), K$ is the permeability of the mush given by the Kozeny-Carman relationship, $\mu$ is the liquid viscosity, and $\dot{\varepsilon}_{\perp}^{p l}$ is strain rate perpendicular to the heat flow. For an axi-symmetric thermomechanical simulations, this strain rate is given by ${ }^{[22]}$

$$
\dot{\varepsilon}_{\perp}^{p l}=\dot{\varepsilon}_{r}^{p l} \sin \gamma-\dot{\varepsilon}_{z}^{p l} \cos \gamma+\dot{\varepsilon}_{\theta}^{p l}
$$

where $\gamma$ is the angle between the thermal gradient and the radial axis $\theta$ is the hoop direction. The limits of integration for Eqs. 6-8 are defined such that ' 0 ' is near the solidus, and $L$ is the length of the mushy zone. Since at very high $f_{\mathrm{s}}$, dendrite bridging has already occurred and hot tears are unlikely to form ${ }^{[31]}$, the ' 0 ' limit of integration is defined as the point where $f_{\mathrm{s}}=0.98$.

In order to apply the RDG criterion to the magnesium DC casting simulation, a PYTHON script was written to access the ABAQUS results database and to calculate the $\Delta P_{\text {mech }}+\Delta P_{\text {shrink }}$ depression pressure. The script accesses the thermal history of every node in a sequential manner, determining the critical time increment when the fraction solid of each node reaches $f_{\mathrm{s}}=0.98$. At this critical time increment, the heat flux at the node being processed is used to determine the angle of heat flow, and hence the path connecting the current node with the bulk liquidus contour in the casting. At each of the element intersections (vertex, or line) that lie along this path, the relevant variables $\left(\dot{\varepsilon}_{\perp}^{p l}, f_{s}\right.$, and $\left.\frac{d f_{s}}{d t}\right)$ are extracted from the simulation 
database. There are between 20 and 30 such element intersections along the path, depending on the depth of the mushy zone for the specific node being processed. This snapshot in time provides the current mushy zone conditions at the exact instant where hot tearing is most susceptible for the node being processed. Using this data, the mushy zone variation in pressure is calculated as follows,

$$
\begin{aligned}
& F_{i}=\frac{1}{2}\left(\frac{d f_{s, i}}{d T} \dot{T}_{i}+\frac{d f_{s, i-1}}{d T} \dot{T}_{i-1}\right) \cdot\left(x_{i}-x_{i-1}\right)+F_{i-1} \\
& E_{i}=\frac{1}{2}\left(f_{s, i} \dot{\varepsilon}_{\perp, i}^{p l}+f_{s, i-1} \dot{\varepsilon}_{\perp, i-1}^{p l}\right) \cdot\left(x_{i}-x_{i-1}\right)+E_{i-1} \\
& \Delta P_{i}=\frac{1}{2}\left[\beta \mu\left(\frac{F_{i}}{K_{i}}+\frac{F_{i+1}}{K_{i+1}}\right)+(1+\beta) \mu\left(\frac{E_{i}}{K_{i}}+\frac{E_{i+1}}{K_{i+1}}\right)\right] \cdot\left(x_{i+1}-x_{i}\right)+\Delta P_{i+1}
\end{aligned}
$$

where $x_{i}$ is the location of the $i^{\text {th }}$ intersection point along the mushy zone line projection. Note that the $F_{i}$ and $E_{i}$ are evaluated by integrating from $x=0$ to $x=L$ whereas $\Delta P_{i}$ is evaluated by integrating from $x=L$ to $x=x_{i}$. This arises from the boundary conditions - i.e. the solid velocity $v_{\mathrm{s}, \mathrm{y}}$ is 0 at $x=0$ while $\Delta P_{i}=0$ at the liquidus. The trapezoid rule has been used to integrate $F, E$, and $\Delta P$.

\section{E. Model Validation}

In order to provide data necessary for model validation, a plant trial was conducted at the Timminco Metals casting facility located in Haley, Ontario, Canada. A series of six AZ31 billets with the same dimensions as the model domain were cast using three casting speeds and three water flow rates. K-type thermocouples were used to record the thermal history in the billet, dummy block and mold during each cast at a rate of $10 \mathrm{~Hz}$. Figure 1 shows the locations of four thermocouples $(A-D)$ within the billet used to measure the evolution of temperature with time. The thermocouples cast into the billet were sheathed in a flexible stainless steel over braid to provide protection from the melt. The displacement of the bottom of the billet relative to the dummy block was measured using Linear Voltage Displacement Transducers (LVDT). Further details of the plant trial and the casting conditions used are given in ${ }^{[14]}$.

Following the casting trial, the billet representing typical casting conditions (casting speed equal to $50 \mathrm{~mm} / \mathrm{min}$ and cooling water flow rate equal to $4.5 \mathrm{l} \mathrm{s}^{-1}$ ) was sent to NRC's Canadian Neutron Beam Centre (CNBC) at the Chalk River Laboratories in Ontario, Canada, for residual strain measurements via neutron diffraction. Measurements were performed on the L3 diffractometer, which is a specific instrument built at CNBC for conducting strain 
mapping on large objects. This facility offers computer-controlled translation/rotation systems that are designed for objects weighing up to 5 tons. In the current work, the residual strain measurements were carried out using neutrons of wavelength $1.754 \AA$ at a monochromator take-off angle of $79.876^{\circ}$ to provide high angular resolution. This wavelength corresponds to the (2-12) diffraction plane, and was selected for these measurements because it has been shown in other HCP materials ( $\mathrm{Zr}$ and $\mathrm{Ti}$ ) to accumulate little or no Type II stresses, and therefore has little anisotropy. The sampling volume was $10 \times 10 \times 10 \mathrm{~mm}^{3}$ in all three principle axes. The lattice spacing was determined using Bragg's law with the lattice strain calculated based on the shift in the Bragg angle. The elastic strains were measured in three orientations consistent with the $r, z$, and $\theta$ direction on the billet at a series of locations along the outer diameter and the base of the billet. Additional details on the residual strain measurements are given in ${ }^{[32]}$.

\section{RESULTS AND DISCUSSION}

Firstly, a series of thermal and stress contour plots are provided to give an overview of their distribution within a typical casting. Secondly, the thermal and residual strain predictions made by the model are validated against the experimental data. Thirdly, the evolution of stresses and strains during solidification are examined. Finally, the model is used to investigate hot tearing susceptibility in different regions of the billet and under different casting conditions.

\section{A. Model Results}

Figure 5 shows contour plots of temperature (Fig. 5a) and hoop stress (Fig. 5b) in the cross-section of the billet after $505 \mathrm{~s}, 1050 \mathrm{~s}$ and $1490 \mathrm{~s}$. The hoop stress is shown since, as per Equation (9), it is considered to be the major driving force for crack initiation and hot tear propagation in billet casting. The mushy zone has been outlined in the figures at $505 \mathrm{~s}, 1050 \mathrm{~s}$ and 1490 s using a black line. As can be seen from the thermal contours, cooling is dominated by the secondary water cooling, which strikes the ingot surface just below the mould. Since the mushy zone does not appear to be changing size or shape relative to the mould in the three thermal contours shown it would appear that steady-state thermal conditions are reached before $505 \mathrm{~s}$. At the ingot center the pool depth is estimated to be $0.2 \mathrm{~m}$ by $505 \mathrm{~s}$.

As shown in the contours presented in Figure 5(b), the surface of the billet below the mould is in a state of tensile stress, due to the thermal contraction induced by the cooling water sprays. Moving down the ingot, as the thermal gradient moderates, the surface stress 
state becomes compressive while the center region is in tension to maintain internal equilibrium. The length of the surface region in compression and the length of the center region in tension, below the water impingement zone, increases with increasing cast length. The distribution of stress arises because at the surface of the ingot, at the point of secondary cooling water impingement, the tensile stresses that are generated exceed the yield point of the material resulting in the accumulation of tensile plastic strain. Once this material cools it is placed into compression and the interior material into tension. The maximum value of the hoop stress is $\sim 150 \mathrm{MPa}$, well above the yield point of the as-cast structure. It can also be seen that the mushy zone remains in a low state of tensile stress throughout the casting process. While this stress value is low, it has exceeded the material's yield limit resulting in permanent deformation.

\section{B. $\quad$ Model Validation}

Comparison of measured and predicted temperatures

Although a full validation of the thermal FE predictions has previously been presented ${ }^{[14]}$, a summary of these results are shown here to demonstrate the capabilities of the current coupled thermal-mechanical model. In models of the DC casting process, this coupling is especially important in the transient start-up regime since the billet distortions may affect the heat transfer ${ }^{[16]}$ between the billet and the dummy block (surface $\Gamma_{4}$, Figure 1 ). The model predicted very little billet base distortion, consistent with what was observed during the plant trials conducted for this investigation. Consequently, the heat transfer boundary condition at this interface is assumed to be a function of temperature only. A fully-coupled thermomechanical formulation, as opposed to a sequential formulation, was necessary in order to incorporate the RDG hot tearing criterion within the ABAQUS framework.

In Figure 6, the model predictions in the start-up regime are compared with the measured data obtained from the typical casting conditions at the plant trial. The thermocouples $A$ and $B$ were located 8 and $160 \mathrm{~mm}$ from the billet surface and $8 \mathrm{~mm}$ above the lip of the dummy block. It is evident from the figure that the model is able to reproduce the thermal behavior within the start-up regime at locations both close to the surface and near the centre of the billet. Figure 7 provides an assessment of model's ability to reproduce the billet temperatures in the steady-state regime by comparing the predicted and measured temperature response at thermocouples $C$ and $D$, located 5 and $45 \mathrm{~mm}$ from the billet surface and $200 \mathrm{~mm}$ above the dummy block lip. The results shown in Figure 7 also indicate a good agreement between the 
predicted temperatures in the coupled thermal-stress model, and the experimentally measured temperatures curves.

\section{Comparison of measured and predicted residual strains}

Validation of the stress-strain predictions from the billet DC casting simulation was performed by comparing the elastic strains predicted by the model to the residual elastic strains measured by neutron diffraction. To simulate the cooling of the billet to room temperature after casting is completed, the model was run for an additional $2000 \mathrm{~s}$ after the final horizontal layer of elements was added. Although the measurements do not provide the strain history of the billet, they provide insight into the model's ability to correctly predict the final residual strain state. Figures 8-10 show the comparison between the measured and predicted radial, axial, and hoop strains as a function of height from the bottom of the billet. In the case of the radial and hoop orientations, the strains $20 \mathrm{~mm}$ below the billet surface are compared. In the case of the axial orientation, a location $10 \mathrm{~mm}$ below the billet surface is used. Note that the scatter / error bars in the measured values of strain are based on the fact that a given grain has an average lattice spacing determined by the adjacent grains in the polycrystalline subset. The Bragg peak is the sum of scattering from all the grains sampled in the gauge volume, yet all these grains have slightly different lattice spacing. Since the measured grain size is around $250 \mu \mathrm{m}$, the number of correctly oriented grains in the gauge volume can be quite small and thus large fluctuations in the Bragg angle can occur, which corresponds to scatter in the strain measurement.

As can be seen in Figure 8, the predicted radial strains show good agreement with the measured data. The predicted axial component of the residual strain, Figure 9, shows qualitatively the correct trend of decreasing residual strain with increasing distance away from the bottom block. However, the magnitude of the prediction is consistently, and significantly, lower. As can be seen in Figure 10, relatively poor agreement was obtained in the comparison between the predicted and measured hoop strains. The predicted hoop strain away from the bottom block is compressive. In this region, there is a substantial variation in the measured hoop strains from compressive through to tensile. The error-bars in the measured residual hoop strains are significantly larger than for the axial and radial cases which may be indicative of the quality of the measurement for this orientation.

The comparisons shown in Figures 8-10 suggest that the model predictions compare adequately to the experimental measurements. However, a strong quantitative validation exists only for the strain in the radial direction. One possible explanation for the lack of 
quantitative agreement in the hoop and axial directions is the effect of the steel frame which was cast into the ingot to support the thermocouples used for the thermal validation. As the steel exhibits a different thermal contraction behavior than the magnesium it will alter the stress field. A second explanation may be related to the use of a rate-independent formulation for the inelastic constitutive behavior in the model. This formulation ignores both time dependent deformation phenomena, which may be occurring to some extent in AZ31 at elevated temperatures, and rate-dependent plasticity effects, which may be important at temperatures above $0.5 \cdot T_{\text {sol }}$.

\section{C. $\quad$ Predicted stress and strain evolution in the billet}

The thermo-mechanical simulation can be used to provide a detailed description of the evolution of stresses and strains during the industrial casting of magnesium alloys. The predicted evolution in hoop stress and hoop strain at three locations within the billet have been chosen for comparison. Referring to Figure 1, the locations are labeled Point $I(10 \mathrm{~mm}$ above the billet lip and on the centerline of the casting), Point $I I$ (10 $\mathrm{mm}$ above the billet lip and $10 \mathrm{~mm}$ from the exterior surface of the casting), and Point III (200 mm above the billet lip and on the centerline of the casting). Points $I$ and $I I$ compare the variation in deformation at two radial locations in proximity to the base of the casting with one prone to crack formation the other not, while Points $I$ and $I I I$ compare the variation in deformation in the centre of the ingot at two vertical locations prone to crack formation.

The predicted evolution in hoop stress and hoop strain in the start-up regime, at Points $I$ and $I I$ are shown in Figure 11. The evolution in temperature at these two locations is also given to provide an indication of the temperature regime over which they develop. As can be seen in Figure 11a, there is a difference in the cooling behavior between the two locations beginning at $\sim 400$ s consistent with the cooling water reaching the surface of the billet. There is also a great deal of variation in the plastic hoop strain. As can be seen in the figure, the magnitude of tensile plastic strain at Point $I$ is approximately $30 \%$ larger than Point $I I$ during solidification. Below the solidus temperature, the tensile strain rises sharply near the surface of the casting at Point II, due to the thermal contraction, while the strain near the centerline remains small. In Figure 11b, the predicted evolution in hoop stress is shown. The data indicates a large change in the stress state as a function of time. The near-surface hoop stress (Point II) contains a peak tensile value of $\sim 40 \mathrm{MPa}$ but then transitions to a compressive stress at longer times after this region cools down to below $200^{\circ} \mathrm{C}$ whereas the center-line hoop stress has a local maximum just at the end of solidification. The stress then transitions 
to compressive below the solidus, followed by a return to tensile values during the final cooling. The peak value at Point $I$ is $\sim 50 \mathrm{MPa}$

The predicted evolution in hoop stress and hoop strain along the center-line, at Points $I$ and $I I I$ are shown in Figure 12. As can be seen in this figure, the hoop strain at Point $I I I$ is mainly compressive during the solidification and subsequent cooling at this location whereas Point $I$ is undergoing tensile deformation during solidification. The two stress curves are relatively similar; with the offset in the sudden increase in stress due the relative time at which the adjacent outer material leaves the secondary cooling regime and cools down. Based on the results of Figures 11 and 12, it is clear that the region near Point $I$, i.e. the center-line of the billet in the initial stages of casting, is most susceptible to hot tearing since this region contains the largest tensile strains and stresses during solidification. Although the final strain value is larger for Point $I I$, and the final stress value is larger for Point $I I I$, the deformation during solidification is most extreme at Point $I$.

\section{Hot Tearing Predictions}

As described in Section 3-D, the decrease in pressure within the mushy zone due to mechanical and shrinkage effects has been calculated using Equations (10 - 12). Larger values of this depression pressure (pressure drop) indicate an increased risk of hot tearing. Figure 13 shows the radial variation in depression pressure at different heights $(0.01 \mathrm{~m}, 0.1 \mathrm{~m}$, $0.3 \mathrm{~m}$, and $0.5 \mathrm{~m}$ ) above the dummy block. As can be seen in the figure, the largest depression pressure of $\sim 210 \mathrm{kPa}$ appears right above the dummy block and $10 \mathrm{~mm}$ away from the billet center. Thus, the model predicts the largest susceptibility at the base of the billet and quite close to the center. This finding is consistent with both industrial observations and earlier simulations of the DC billet casting process in aluminum alloys ${ }^{[22]}$.

The utility of simulations is that one can vary the process parameters to determine their effects on thermo-mechanical behavior, and defects. Figure 14 shows the axial variation in depression pressure at the billet center-line calculated using Equations (10 - 12) for three different casting speeds: 40, 50, and $75 \mathrm{~mm} / \mathrm{min}$. Two observations can be made. Firstly, as also observed in Figure 13, the depression pressure is quite small in regions of the casting greater than $\sim 80 \mathrm{~mm}$ above the base of the billet. Secondly, the depression pressure appears to increase linearly with increasing casting speed. Hence, higher casting speeds will lead to increased hot tearing. This finding is also consistent with industrial observations. 


\section{V.SUMMARY AND CONCLUSIONS}

A thermal-mechanical model of DC casting of AZ31 magnesium billets has been developed which includes the billet, dummy block and center bolt geometry. The thermal portion of the model has been validated against measured data obtained from the industrially cast billets instrumented with thermocouples embedded at various locations. The mechanical portion of the model was validated against strain measurements performed using neutron diffraction at the Canadian Neutron Beam Centre in Chalk River, Ontario, Canada. Overall, the results show that the model is able to quantitatively describe the evolution of temperature in the billet and qualitatively predict the development of residual stresses/strains. Furthermore, the evolution of strain and stress at key locations in proximity to the base of the ingot predicted by the model were found to be consistent with where hot tears are observed industrially. The pressure-based RDG hot tearing criterion was applied to calculate the mushy zone depression pressure and quantitatively evaluate the hot tearing susceptibility. The results of this application corroborate industrial findings in terms of the location of the as well as the influence casting speed has; faster casting speeds tend to exacerbate hot tear formation.

\section{ACKNOWLEDGMENTS}

The authors are grateful to the Natural Sciences and Engineering Research Council of Canada (NSERC) for providing financial support of this project in the form of a Strategic Grant, to Timminco Metals for technical support and access to their plant to collect data, and to the National Research Council's Canadian Neutron Beam Centre, in particular Ron Rogge, for access to their neutron diffraction measurement facility. 


\section{LIST OF FIGURES}

Figure 1 - Schematic of DC casting process used for magnesium billet casting, calculation domain, the relevant surfaces $(\Gamma 1$ to $\Gamma 8)$ for application of boundary conditions, the thermocouple locations (A-D) during the plant trial, and the points (IIII) of interest for the stress-strain analysis.

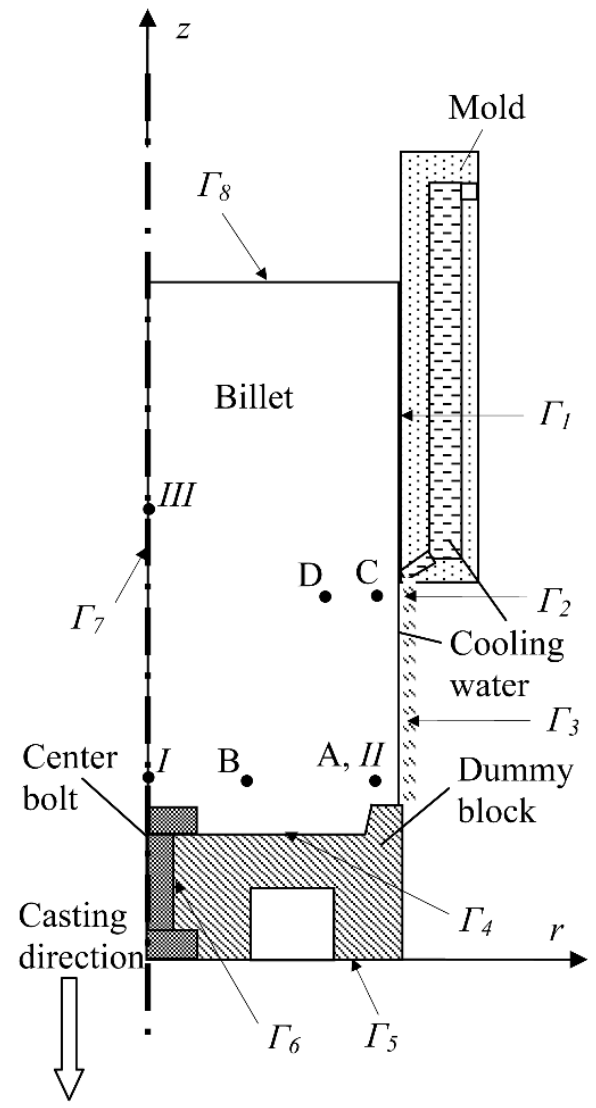

Figure 2 - The elastic modulus-temperature relationship, used in the FE model.

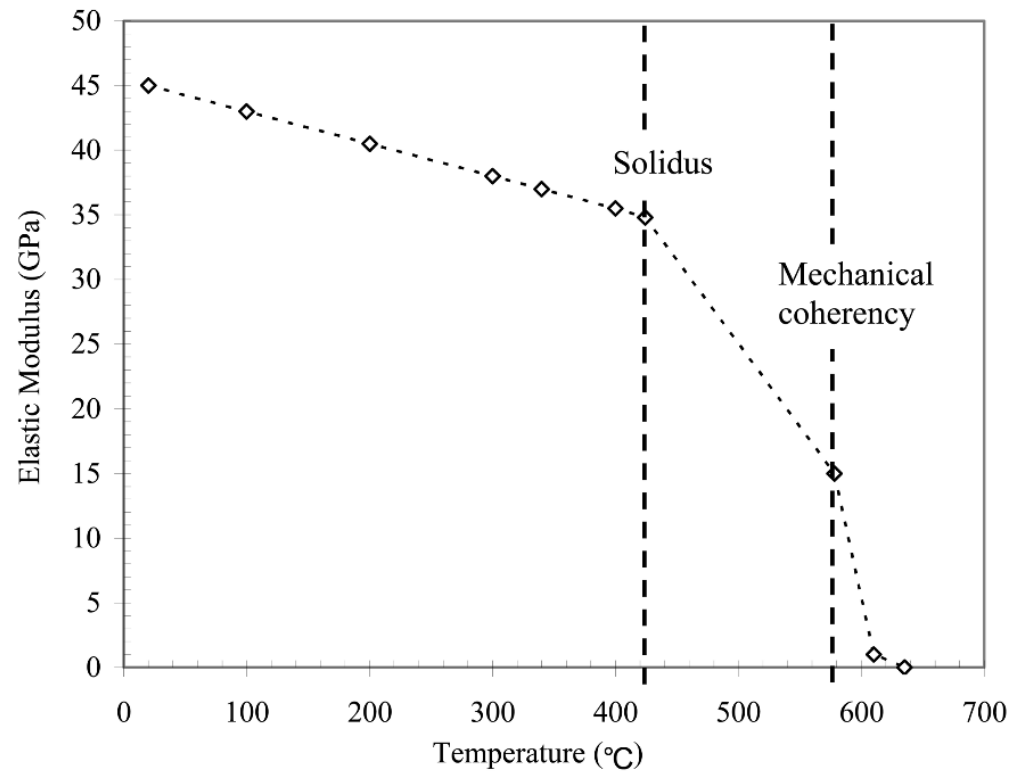


Figure 3 - Thermal strain and the corresponding thermal expansion coefficient used in the model.

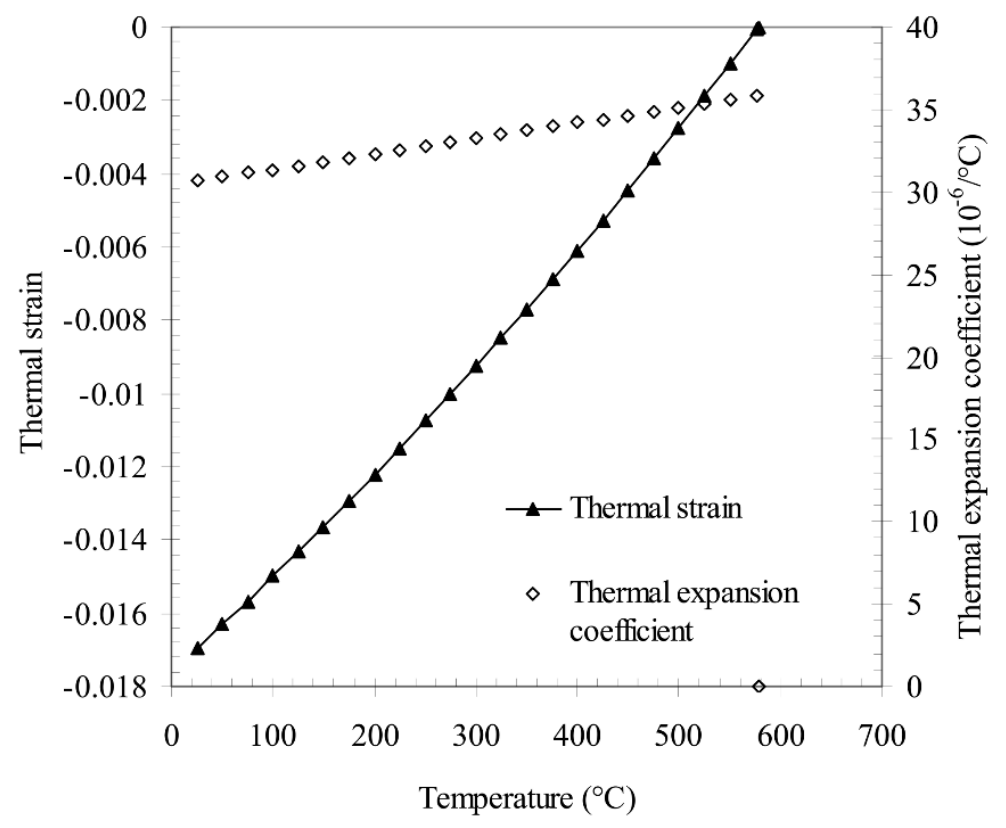

Figure 4 - Measured constitutive behavior of AZ31 at a strain rate of $0.001 \mathrm{~s}^{-1}$, using the Gleeble 3500 at UBC.

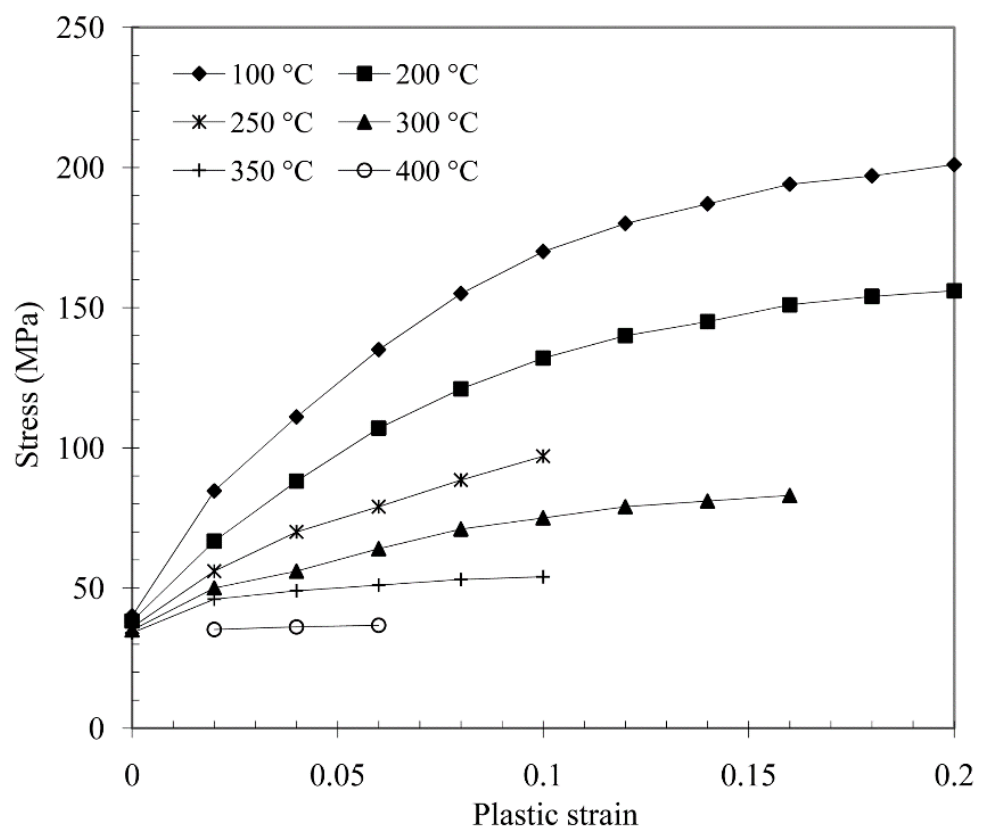


Figure 5 - Contour plots showing the evolution in (a) temperature and (b) hoop stress predicted by the model at $505 \mathrm{~s}, 1050 \mathrm{~s}$, and $1490 \mathrm{~s}$. The mushy zone is highlighted via a black contour line, while the location of the mould is given by a checkered rectangle.
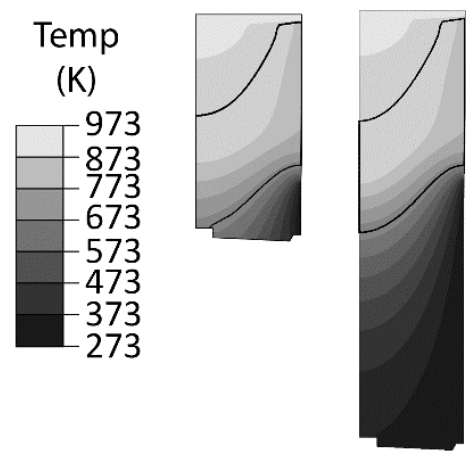

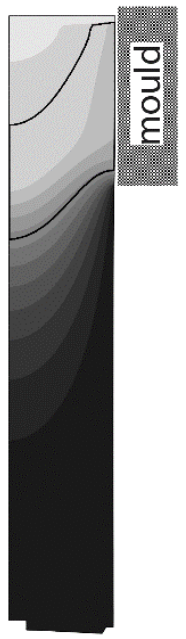

a)
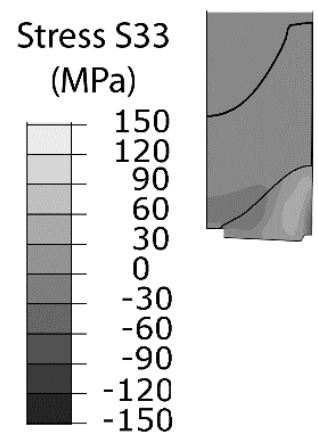

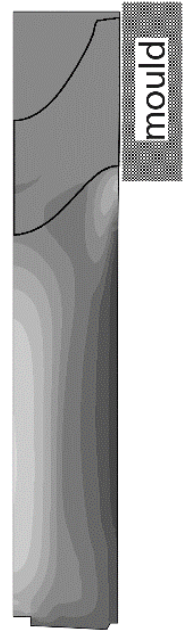

b)

Figure 6 - Comparison of predicted and measured temperatures at locations A and B within the start-up regime for the typical casting conditions.

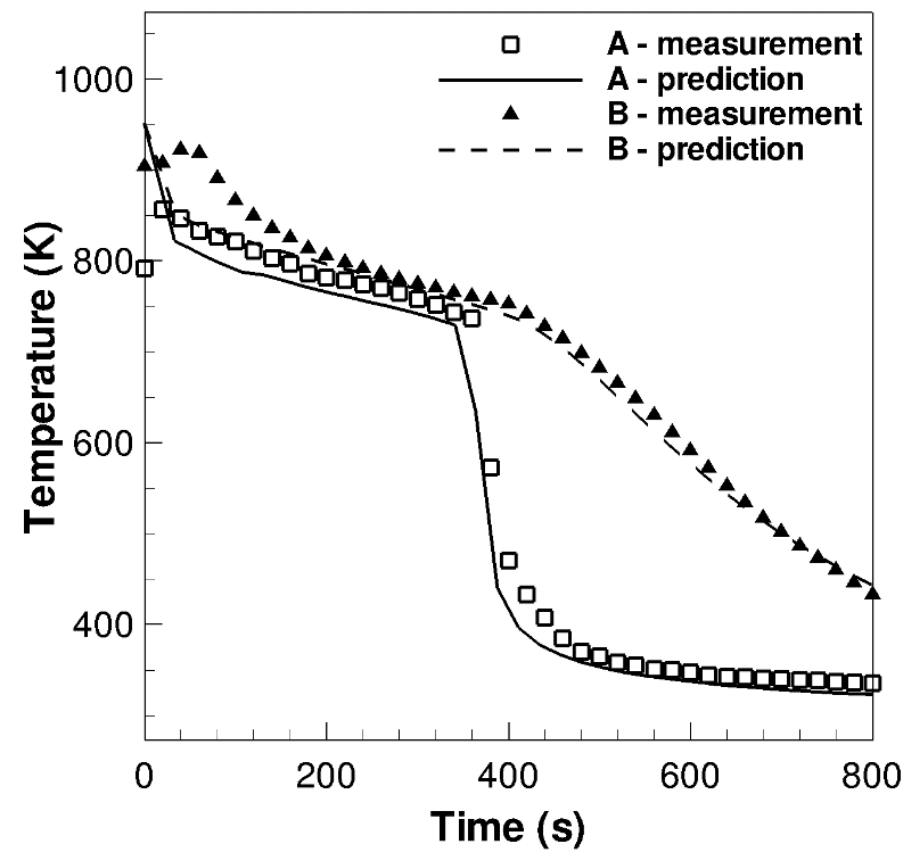


Figure 7 - Comparison of predicted and measured temperatures at locations C and D within the steady-state regime for the typical casting conditions.

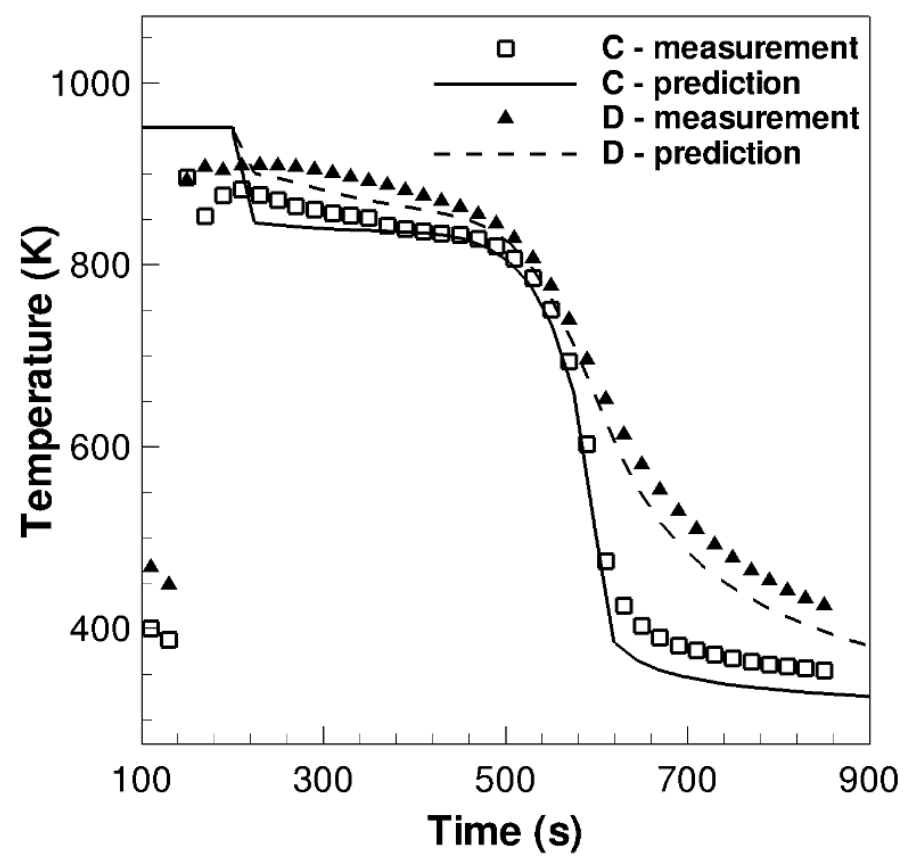

Figure 8 - Comparison of the measured and predicted radial elastic strains $20 \mathrm{~mm}$ from the billet surface as a function of height away from the base of the billet.

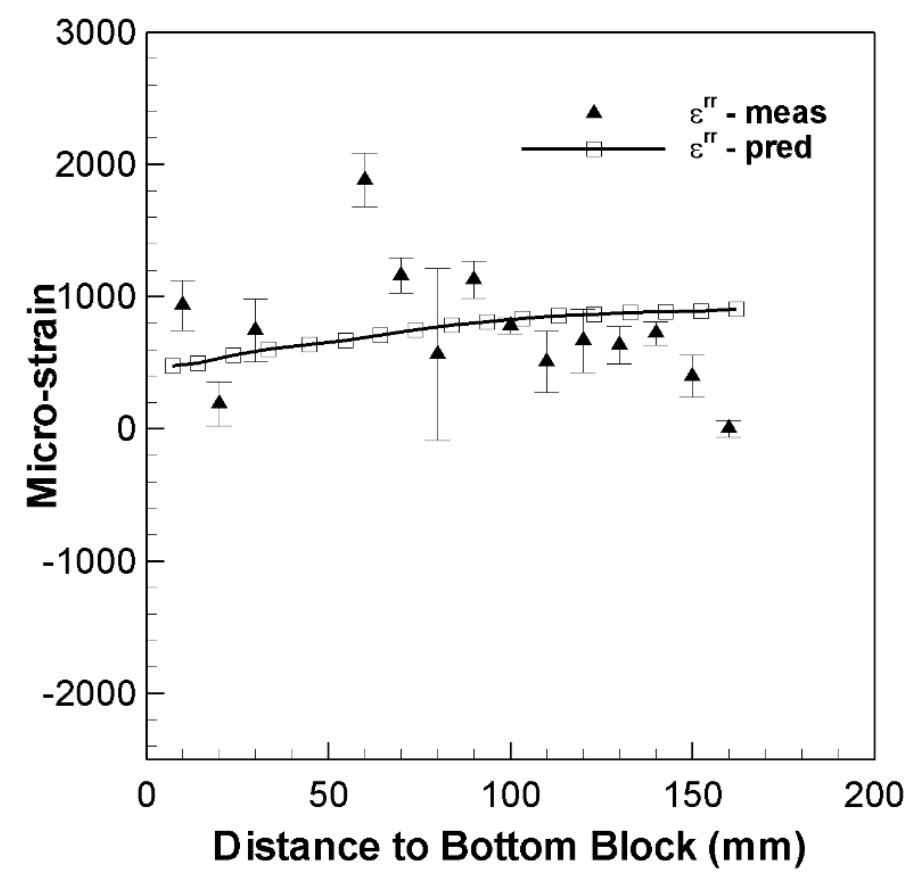


Figure 9 - Comparison of measured and predicted axial elastic strains $10 \mathrm{~mm}$ from the billet surface as a function of height away from the base of the billet.

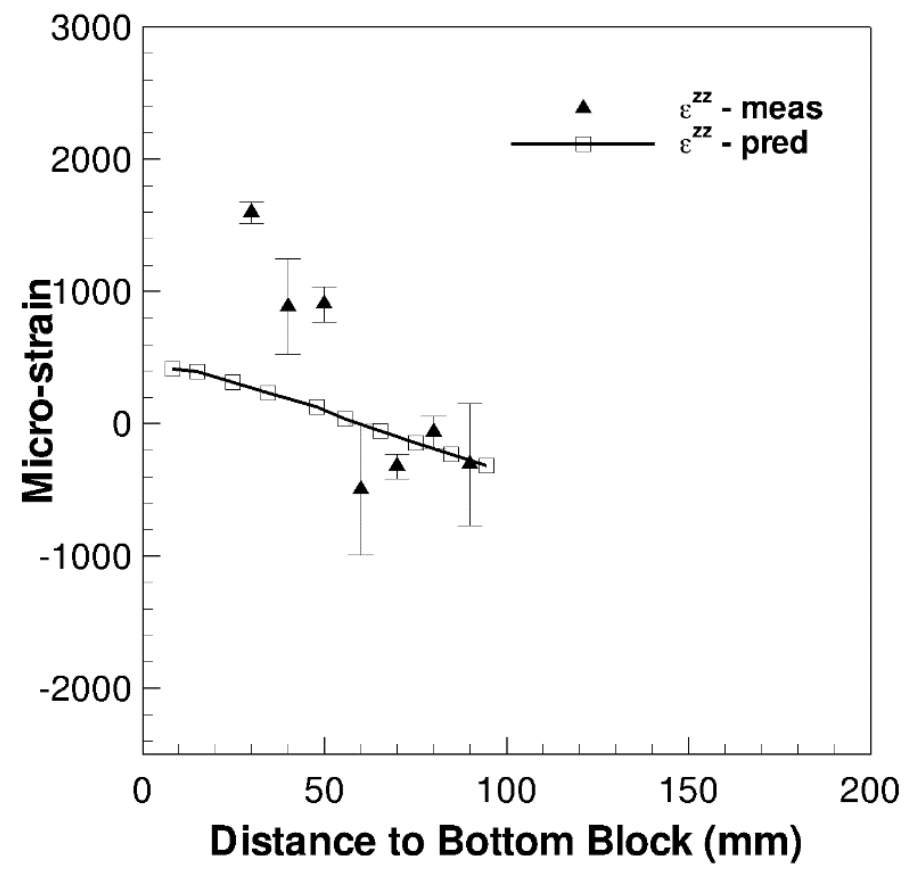

Figure 10 - Comparison of measured and predicted hoop strains $20 \mathrm{~mm}$ from the billet surface as a function of height away from the base of the billet.

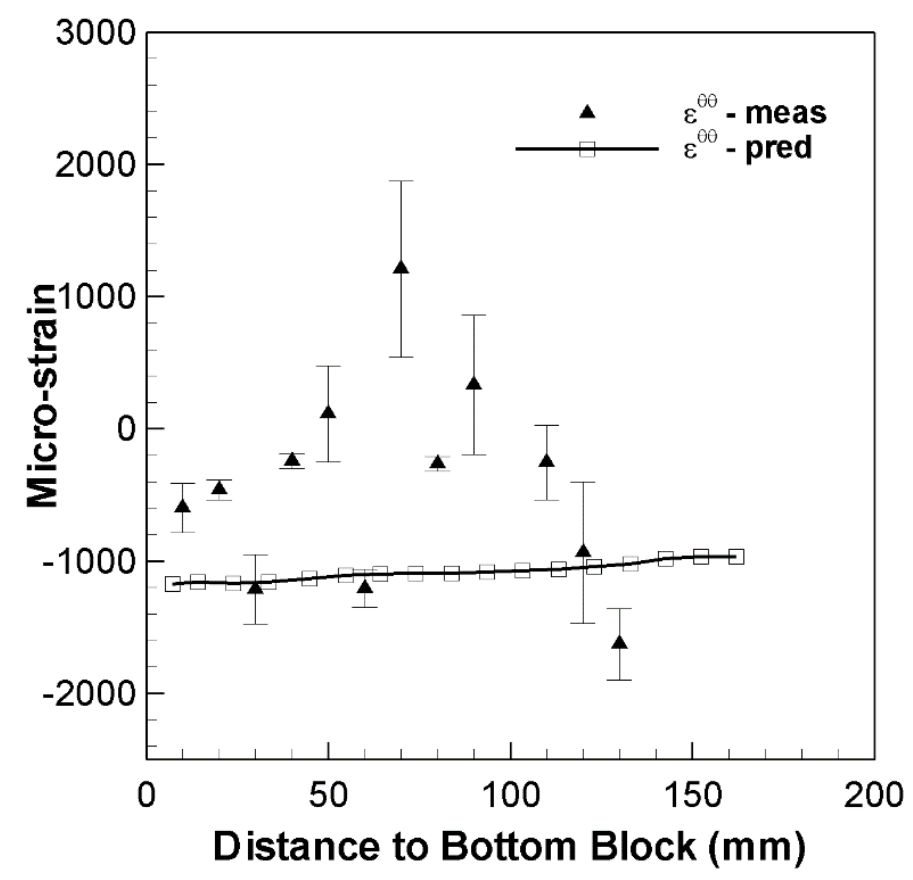


Figure 11 - The simulated (a) evolution in temperature and plastic strain $\varepsilon_{\mathrm{pl}}{ }^{\theta \theta}$ and (b) evolution in temperature and stress $\sigma^{\theta \theta}$ for Point $I$ and Point $I I$.

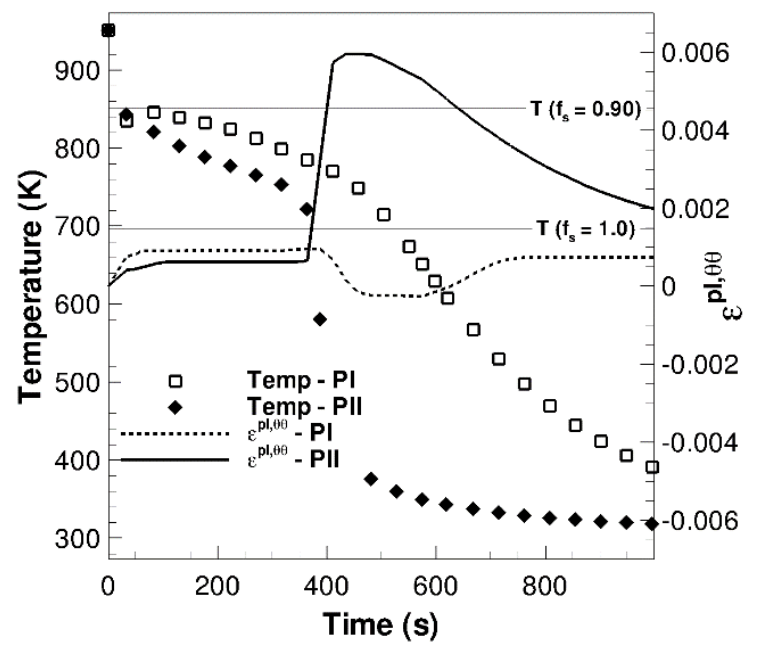

a)

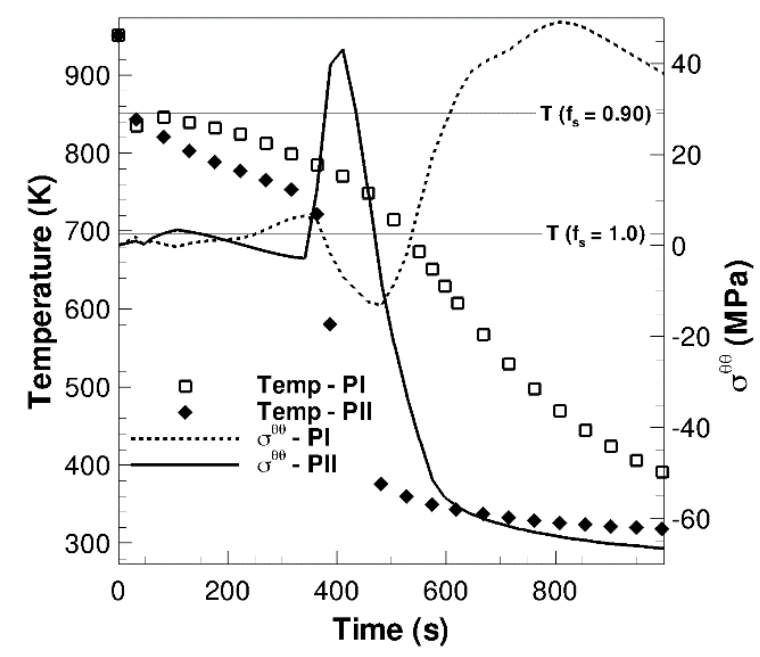

b)

Figure 12 - The simulated (a) evolution in temperature and plastic strain $\varepsilon_{p l}{ }^{\theta \theta}$ and (b) evolution in temperature and stress $\sigma^{\theta \theta}$ for Point $I I$ and Point $I I I$.

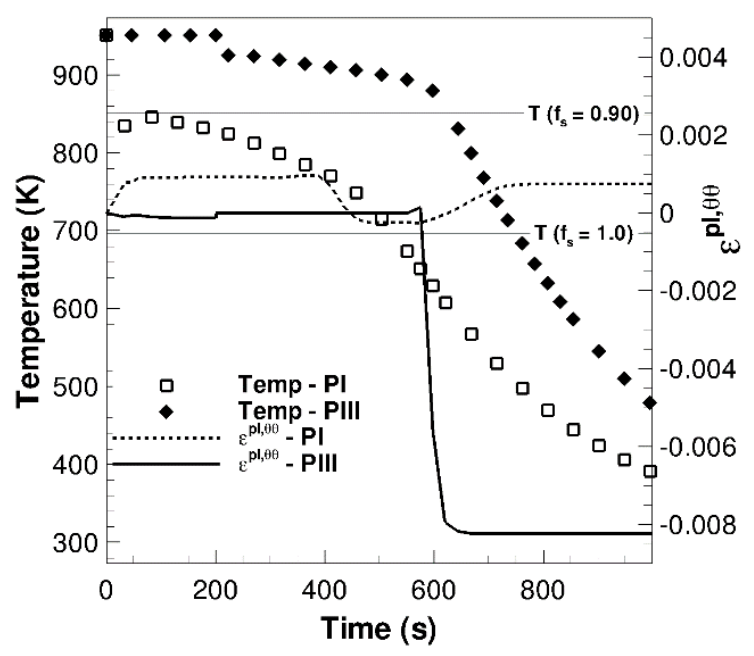

a)

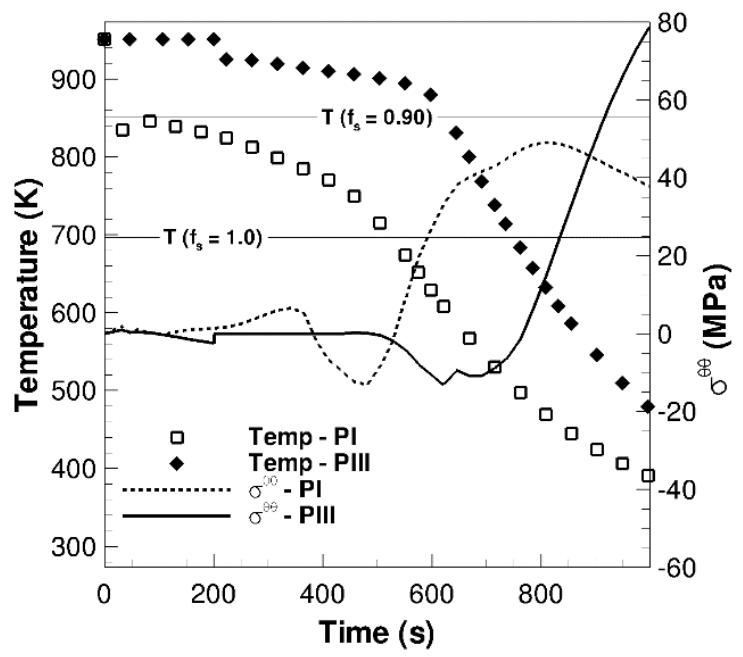

b) 
Figure 13 - Predicted variation in depression pressure as a function of radius at various heights above the dummy block.

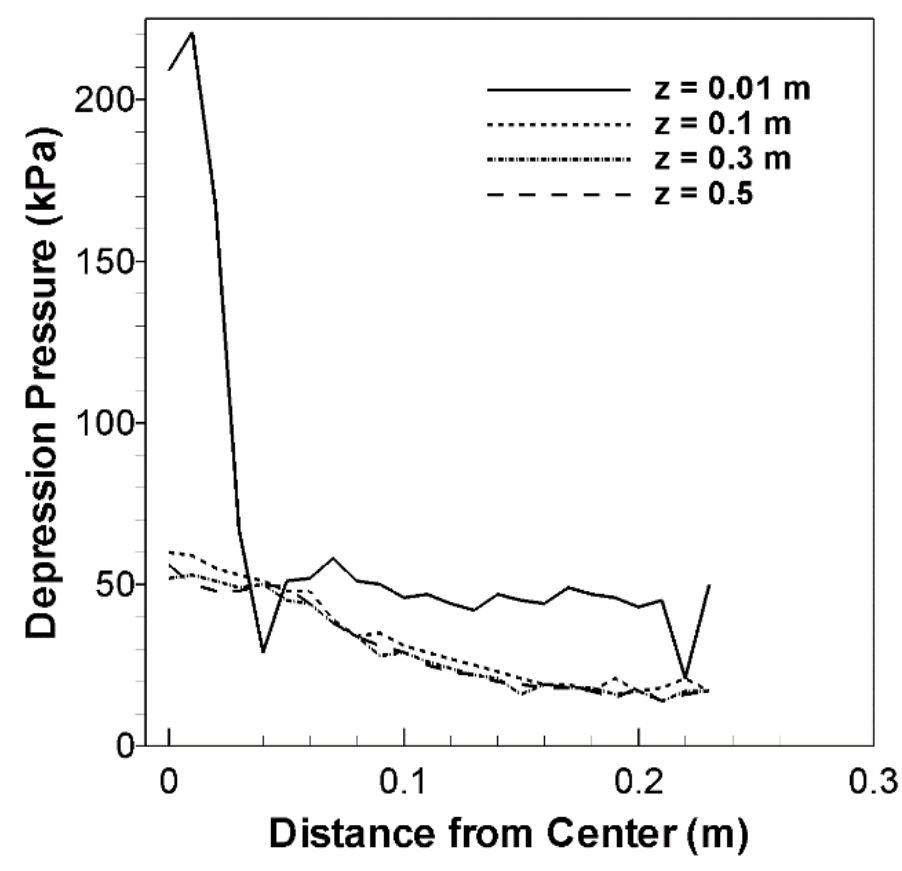

Figure 14 - Predicted variation in depression pressure as a function of height above the bottom block along the center-line for casting speeds of 40,50 , and $75 \mathrm{~mm} / \mathrm{min}$.

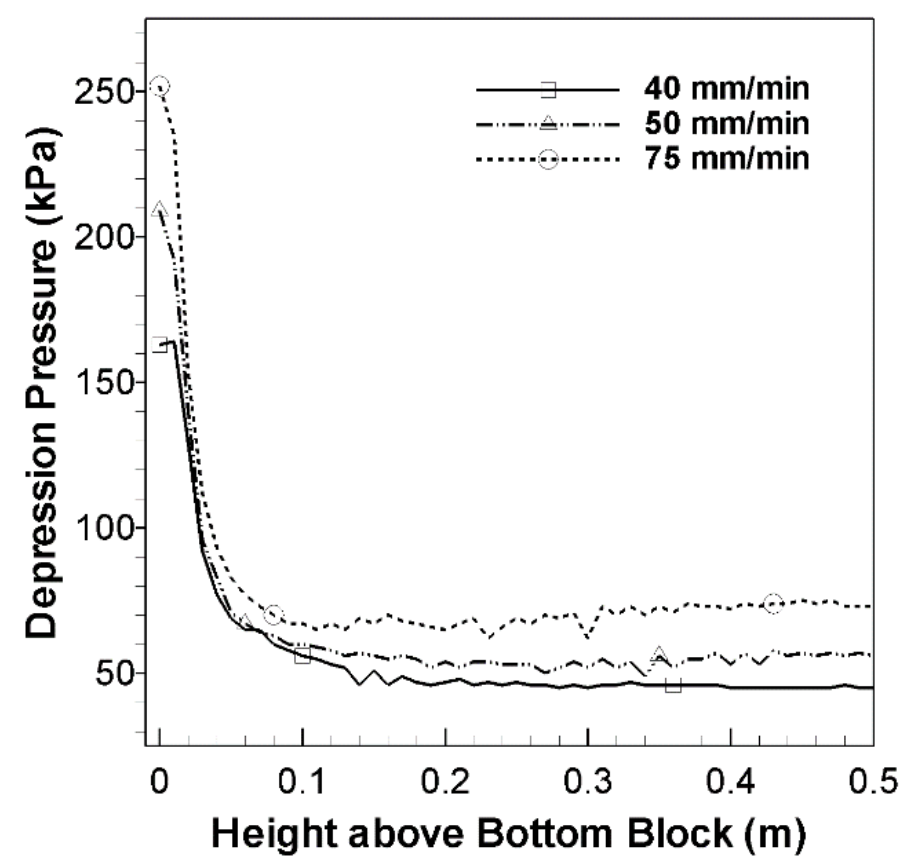




\section{References}

1. P.W. Baker and P.T. McGlade: Light Metals 2001, J. Anjier, ed., TMS, New Orleans, LO, 2001, pp. 855-62.

2. D.G. Eskin, Suyitno and L. Katgerman: Prog. Mater. Sci., 2004, vol. 49, pp. 629-711.

3. J. Grandfield, C.C. Young, K. Oswald and A.P. Baker: Eighth Australasian Conference on Aluminum Cast House Technology, P. Whiteley, ed., TMS, Brisbane, Australia, 2003, pp. 215-21.

4. J.F. Grandfield: Aluminum Transactions (USA), 2000, vol. 3, pp. 41-51.

5. A.B. Phillion, S.L. Cockcroft and P.D. Lee: Scripta Mat. , 2006, vol. 55, pp. 489-92.

6. I. Farup, M. Rappaz and J.M. Drezet: Acta Mater., 2001, vol. 49, pp. 1261-69.

7. J.B. Mitchell, S.L. Cockcroft, D. Viano, C.J. Davidson and D. St John: Metall. Mater. Trans. A, 2007, vol. 38, pp. 2503-12.

8. L.Y. Zhao, Baoyin, N. Wang, V. Sahajwalla and R.D. Pehlke: Int. J. Cast Met. Res., 2000, vol. 13, pp. 167-74.

9. W.S. Pellini: Foundry, 1952, pp. 125-37.

10. D. Viano, D. StJohn, J. Grandfield and C. Caceres: Light Metals 2005, H. Kvande, ed., TMS, San Fransicso, CA, 2005, pp. 1069-73.

11. D.C. Weckman and P. Niessen: Metall. Trans B, 1982, vol. 13B, pp. 593-602.

12. D.J.P. Adenis, K.H. Coats and D.V. Ragone: J. Inst. Metals, 1963, vol. 91, pp. 395-\&.

13. S.G. Hibbins: Intl Symp Light Metals, METSOC-CIM, Calgary, CA, 1998, pp. 265-80.

14. H. Hao, D.M. Maijer, M.A. Wells, S.L. Cockcroft, D. Sediako and S. Hibbins: Metall. Mater. Trans. A, 2004, vol. 35A, pp. 3843-54A.

15. J. Sengupta, S.L. Cockcroft, D.M. Maijer, M.A. Wells and A. Larouche: Metall. Mater. Trans. B, 2004, vol. 35, pp. 523-40.

16. J. Sengupta, S.L. Cockcroft, D.M. Maijer and A. Larouche: Mater. Sci. Eng. A, 2005, vol. 397, pp. 157-77.

17. J.M. Drezet and M. Rappaz: Metall. Mater. Trans. A, 1996, vol. 27A, pp. 3214-25.

18. M. M'Hamdi, A. Mo and H.G. Fjaer: Metall. Mater. Trans. A, 2006, vol. 37A, pp. 306983.

19. H.G. Fjaer and A. Mo: Metall. Trans. B, 1990, vol. 21, pp. 1049-61.

20. A.J. Williams, T.N. Croft and M. Cross: Metall. Mater. Trans. B, 2003, vol. 34B, pp. 727-34B.

21. M. Rappaz, J.M. Drezet and M. Gremaud: Metall. Mater. Trans. A, 1999, vol. 30, pp. 449-55.

22. J.M. Drezet and M. Rappaz: Light Metals 2001, J. Anjier, ed., TMS, New Orleans, LO, 2001, pp. 887-93.

23. Suyitno, W.H. Kool and L. Katgerman: Metall. Mater. Trans. A, 2005, vol. 36A, pp. 1537-46.

24. A.B. Phillion, S.L. Cockcroft, J. Sengupta and D.M. Maijer: Light Metals 2005, H. Kvande, ed., TMS, San Francisco, CA, 2005, pp. 1063-68.

25. A.B. Phillion, D. Maijer and S.L. Cockcroft: Model Casting, Welding \& Adv Solidif Proces XI, C. A. Gandin and M. Bellet, eds., TMS, Opio, FR, 2006, pp. 807-14.

26. D.J. Lahaie and M. Bouchard: Metall. Mater. Trans. B, 2001, vol. 32, pp. 697-705.

27. S.R. Lampman, T.B. Zorc, S.D. Henry, J.L. Daquila and A.W. Ronke, eds., Metals Handbook, vol. 2, ASM INTERNATIONAL, Metals Park, OH, 1990, p. 481.

28. M.M. Avedesian and H. Baker, eds., Magnesium and Magnesium Alloys, ASM International, Metals Park, Ohio, USA, 1999, 258.

29. C.M. Estey, S.L. Cockcroft, D.M. Maijer and C. Hermesmann: Mater. Sci. Eng. A, 2004, vol. 383, pp. 245-51. 
30. J.A. Dantzig and M. Rappaz: Solidification, EPFL Press, Lausanne, 2009.

31. M. Rappaz, A. Jacot and W.J. Boettinger: Metall. Mater. Trans. A, 2003, vol. 34, pp. 467-79.

32. H. Hao, D.M. Maijer, M.A. Wells, S.L. Cockcroft and R.B. Rogge: Magnesium Technology, 2005, pp. 223-28. 